\title{
Urinary tract anomalies in children with hypospadias
}

\author{
Tamara Faundez $\cdot$ Vincent Chariatte $\cdot$ \\ Francois Cachat
}

Accepted: 12 August 2010/Published online: 24 August 2010

(C) Springer-Verlag 2010

Sir,

We read with great interest the article of Gupta et al. [1] reporting their experience with routine ultrasonography (US) screening in children with hypospadias. This is an extremely welcomed study. Studies screening children with hypospadias in a prospective manner with uroradiological exams are scarce, the last one was published 20 years ago [2]! Gupta et al. screened 65 children with hypospadias for congenital anomalies of their upper or lower urinary tract. They found that $18 \%$ of their patients had abnormal US findings, and therefore favor US screening in children with hypospadias. At this point, we would like to make the following comments.

Although anomalies of the upper or lower urinary tract have been found to be quite common in children with hypospadias [3-5], we think that their prevalence should be analyzed in the light of their definite clinical significance, rather than their mere existence. This is especially important now that we observe a dramatic shift toward a more conservative treatment of low-grade vesicoureteral reflux (VUR) [6, 7] and mild hydronephrosis [8], the most common congenital anomalies found in children with hypospadias [1, 3-5]. Many clinicians would not treat a grade I to II VUR or a mild SFU stage I to II hydronephrosis, medically or surgically, unless symptomatic (urinary tract infection, major obstruction), calling into question the value of such screening. We also doubt that the cystitis

T. Faundez

Regional Hospital of Vevey, Vevey, Switzerland

V. Chariatte $\cdot$ F. Cachat $(\bowtie)$

Department of Pediatrics, University Hospital,

Lausanne, Switzerland

e-mail: francois.cachat@hopital-riviera.ch cases they found were a relevant finding of their US screening for urologic anomalies.

Finally, a large number of major congenital anomalies are nowadays discovered prenatally [9], and this is especially true for anomalies of the kidney and urinary tract such as VUR or hydronephrosis [10]. This will undeniably lower the value of such postnatal screening.

In summary, we feel that the incidence of clinically significant anomalies detected with a postnatal US screening program in children with hypospadias is probably low if one removes the non-significant urinary tract anomalies and also the (significant) anomalies already detected with prenatal US screening program (obviously taking into account the availability of such a program to the population in question). In a time of restricted resources and health care cost containment, this might reduce the cost of unnecessary exams in children with hypospadias. Future studies should take into consideration these two aspects.

\section{References}

1. Gupta L, Sharma S, Gupta DK (2010) Is there a need to do routine sonological, urodynamic study and cystourethroscopic evaluation of patients with simple hypospadias? Pediatr Surg Int, July 13 [published ahead of print]

2. Moore CC (1990) The role of routine radiographic screening of boys with hypospadias: a prospective study. J Pediatr Surg 25:339-341

3. Wu WH, Chuang JH, Ting YC, Lee SY, Hsieh CS (2002) Developmental anomalies and disabilities associated with hypospadias. J Urol 168:229-232

4. Kulkarni BK, Oak SN, Patel MP, Merchant S, Borwankar SS (1991) Developmental anomalies associated with hypospadias. J Postgrad Med 37:140-143

5. Shelton TB, Noe HN (1985) The role of excretory urography in patients with hypospadias. J Urol 134:97-99 
6. Montini G, Rigon L, Zucchetta P, Fregoneses F, Toffolo A, Gobbler D et al (2008) Prophylaxis after first febrile urinary tract infection in children? A multicenter, randomized, controlled noninferiority trial. Pediatrics 122:1064-11071

7. Roussey-Kesler G, Gadjos V, Idres N, Horen B, Ichay L, Leclair MD et al (2008) Antibiotic prophylaxis for the prevention of recurrent urinary tract infection in children with low grade vesicoureteral reflux: results from a prospective randomized study. J Urol 179:674-679

8. Karnak I, Woo LL, Shah SN, Sirajuddin A, Ross JH (2009) Results of a practical protocol for the management of prenatally detected hydronephrosis due to ureteropelvic junction obstruction. Pediatr Surg Int 25:61-67

9. Chitty LS, Hunt GH, Moore J, Lobb MO (1991) Effectiveness of routine ultrasonography in detecting fetal structural abnormalities in a low risk population. BMJ 303:1165-1169

10. Romosan G, Henriksson E, Rylander A, Valentin L (2009) Diagnostic performance of routine ultrasound screening for fetal abnormalities in an unselected Swedish population in 2000-2005. Ultrasound Obstet Gynecol 34:526-533 